\title{
The superoxide anion donor, potassium superoxide, induces pain and inflammation in mice through production of reactive oxygen species and cyclooxygenase-2
}

\author{
N.A. Maioli ${ }^{1}$, A.C. Zarpelon ${ }^{1}$, S.S. Mizokami ${ }^{1}$, C. Calixto-Campos ${ }^{1}$, C.F.S. Guazelli ${ }^{1}$ \\ M.S.N. Hohmann ${ }^{1}$, F.A. Pinho-Ribeiro ${ }^{1}$, T.T. Carvalho ${ }^{1}$, M.F. Manchope ${ }^{1}$, C.R. Ferraz ${ }^{1}$, \\ R. Casagrande ${ }^{2}$ and W.A. Verri Jr. ${ }^{1}$ \\ ${ }^{1}$ Departamento de Patologia, Centro de Ciências Biológicas, Universidade Estadual de Londrina, Londrina, PR, Brasil \\ ${ }^{2}$ Departmento de Ciências Farmacêuticas, Centro de Ciências da Saúde, Hospital Universitário, \\ Universidade Estadual de Londrina, Londrina, PR, Brasil
}

\begin{abstract}
It is currently accepted that superoxide anion $\left(\mathrm{O}_{2}{ }^{-}\right)$is an important mediator in pain and inflammation. The role of superoxide anion in pain and inflammation has been mainly determined indirectly by modulating its production and inactivation. Direct evidence using potassium superoxide $\left(\mathrm{KO}_{2}\right)$, a superoxide anion donor, demonstrated that it induced thermal hyperalgesia, as assessed by the Hargreaves method. However, it remains to be determined whether $\mathrm{KO}_{2}$ is capable of inducing other inflammatory and nociceptive responses attributed to superoxide anion. Therefore, in the present study, we investigated the nociceptive and inflammatory effects of $\mathrm{KO}_{2}$. The $\mathrm{KO}_{2}$-induced inflammatory responses evaluated in mice were: mechanical hyperalgesia (electronic version of von Frey filaments), thermal hyperalgesia (hot plate), edema (caliper rule), myeloperoxidase activity (colorimetric assay), overt pain-like behaviors (flinches, time spent licking and writhing score), leukocyte recruitment, oxidative stress, and cyclooxygenase-2 mRNA expression (quantitative PCR). Administration of $\mathrm{KO}_{2}$ induced mechanical hyperalgesia, thermal hyperalgesia, paw edema, leukocyte recruitment, the writhing response, paw flinching, and paw licking in a dose-dependent manner. $\mathrm{KO}_{2}$ also induced time-dependent cyclooxygenase-2 mRNA expression in the paw skin. The nociceptive, inflammatory, and oxidative stress components of $\mathrm{KO}_{2}$-induced responses were responsive to morphine (analgesic opioid), quercetin (antioxidant flavonoid), and/or celecoxib (anti-inflammatory cyclooxygenase-2 inhibitor) treatment. In conclusion, the well-established superoxide anion donor $\mathrm{KO}_{2}$ is a valuable tool for studying the mechanisms and pharmacological susceptibilities of superoxide anion-triggered nociceptive and inflammatory responses ranging from mechanical and thermal hyperalgesia to overt pain-like behaviors, edema, and leukocyte recruitment.
\end{abstract}

Key words: Superoxide anion; Potassium superoxide; Pain; Inflammation; Oxidative stress

\section{Introduction}

Inflammation-related events such as edema, leukocyte recruitment, and pain are important for the protection of organisms, but excessive and persistent inflammation leads to tissue damage, chronic pain, and organ dysfunction. Therefore, knowledge of inflammation mechanisms is essential to treat inflammatory diseases and to promote host protection and homeostasis (1).

Oxidative stress is an important component of pain and inflammation. Similarly, antioxidants such as the flavonoid, quercetin, inhibit overt pain-like behavior, carrageenan-induced mechanical hyperalgesia, and paw edema by diminishing interleukin-1 $\beta$ production and reducing glutathione (GSH) depletion (2). Quercetin also inhibits leukocyte recruitment (3) and acetic acid-induced colitis in mice (4). This is a consistent effect observed with antioxidants $(5,6)$. Quercetin is considered to be a standard antioxidant flavonoid, because it presents all the structural groups related to antioxidant activity possessed by this class of molecules (2-4).

The role of reactive oxygen species (ROS) in pain and inflammation has been investigated in vivo. For instance, the superoxide dismutase (SOD) mimetics, M40403 and

Correspondence: W.A. Verri Jr.: < waldiceujr@yahoo.com.br > and/or < waverri@uel.br> .

Received June 11, 2014. Accepted November 7, 2014. First published online February 13, 2015. 
TEMPOL, inhibit carrageenan-induced thermal hyperalgesia, paw edema, and cytokine production by preventing the superoxide-induced nitration of $\operatorname{SOD}(7,8)$. Similarly, SOD inhibition by diethyldithiocarbamic acid increases carrageenan-induced paw edema and thermal hyperalgesia (8). The generation of peroxynitrite by the coadministration of pyrogallol (superoxide anion generator) and of a nitric oxide donor (SNAP) also induces thermal hyperalgesia and paw edema (8).

The main inflammatory source of superoxide anion is the complex of phagocytic NADPH oxidase enzymes. Production of superoxide anion and its derivatives is related to opioid tolerance, chemotherapy-induced pain, neuropathic pain, neurogenic pain, and inflammatory pain (9).

Despite current evidence regarding the crucial role of superoxide in pain and inflammation, to our knowledge, there are limited experimental approaches for studying the induction of pain and inflammation directly by superoxide anion. There is evidence that potassium superoxide $\left(\mathrm{KO}_{2}\right)$, a superoxide anion donor, induces thermal hyperalgesia in the Hargreaves method at $20 \mathrm{~min}$ (7) and 60 min (10) after its injection into the paw. However, to further support the use of $\mathrm{KO}_{2}$ for investigating a wide range of superoxide anion-induced inflammatory and pain responses, it remains to be determined whether $\mathrm{KO}_{2}$ induces additional nociceptive behaviors such as mechanical hyperalgesia and overt pain-like behaviors as well as inflammatory responses such as edema and leukocyte recruitment. In this context, we investigated $\mathrm{KO}_{2}$ as a trigger for pain and inflammation in mice and the susceptibility of these responses to the analgesic opioid, morphine, the antioxidant flavonoid, quercetin, and the cyclooxygenase-2 (COX-2) selective inhibitor, celecoxib.

\section{Material and Methods}

\section{Animals}

Male Swiss mice $(25 \pm 5 \mathrm{~g})$ from Universidade Estadual de Londrina were housed in standard plastic cages with free access to food and water, with a 12:12-h light/dark cycle, at $21^{\circ} \mathrm{C}$. Care and handling procedures for the animals were in accordance with the International Association for the Study of Pain (IASP) guidelines and with the approval of the Ethics Committee of the Universidade Estadual de Londrina (process \#71.20 12.68).

\section{Drugs and reagents}

$\mathrm{KO}_{2}(96.5 \%)$ was purchased from Alfa Aesar (USA). Quercetin at 95\% purity was purchased from Acros (USA). Morphine, naloxone, hexadecyl trimethyl ammonium bromide, o-dianisidine dihydrochloride, GSH, EDTA sodium salt, ferric chloride hexahydrate, 2,4,6-tripyridyl-striazine, 2,2' -azino-bis(3-ethylbenzothiazoline-6-sulfonate (ABTS), and 6-hydroxy-2,5,7,8-tetramethylchroman-2-11 carboxylic (Trolox) were purchased from Sigma (USA).

\section{Experimental protocols}

The parameters evaluated were mechanical hyperalgesia; thermal hyperalgesia; paw edema; paw flinches; paw licking; writhing response; total counts of leukocytes, mononuclear cells, and neutrophils; superoxide anion production; pharmacological susceptibility to morphine, quercetin, and celecoxib; oxidative stress methods (ferricreducing ability potential [FRAP], ABTS, and GSH assays); and quantitative polymerase chain reaction (qPCR) for COX-2 mRNA expression. For mechanical hyperalgesia, thermal hyperalgesia, and paw edema, $\mathrm{KO}_{2}$ was administered by the intraplantar (ip/) route at doses of $3-100 \mu \mathrm{g} /$ paw in a final volume of $25 \mu \mathrm{L}$ sterile saline, followed by evaluation after 0.5-7 h. Paw flinches and time spent licking the paw were determined between 0 and $30 \mathrm{~min}$ after $\mathrm{ip} /$ injection of $\mathrm{KO}_{2}(1-30 \mu \mathrm{g} / \mathrm{paw})$, and the total number of writhings was determined between 0 and 20 min after intraperitoneal (ip) injection of $\mathrm{KO}_{2}$ (30$1000 \mu \mathrm{g} /$ cavity, in a final volume of $100 \mu \mathrm{L}$ of sterile saline). Total counts of leukocytes, mononuclear cells, and neutrophils were evaluated $6 \mathrm{~h}$ after ip injection of $\mathrm{KO}_{2}\left(10-100 \mu \mathrm{g} /\right.$ cavity). Superoxide anion levels in $\mathrm{KO}_{2}$ saline solution were determined by reduction of nitrobluetetrazolium (NBT) in vitro.

The pharmacological susceptibility of $\mathrm{KO}_{2}$-induced nociception was determined using the opioid morphine, the antioxidant quercetin, and the COX-2 selective inhibitor celecoxib, as follows. Morphine: mice were treated with morphine $(2-12 \mu \mathrm{g} / \mathrm{paw}, i p l, 20 \mu \mathrm{L}, 30 \mathrm{~min}$ before measurement) and the opioid receptor antagonist naloxone $(30 \mu \mathrm{g} / \mathrm{paw}, \mathrm{ipl}, 1 \mathrm{~h}$ before morphine) or its vehicle. Quercetin: mice were treated with quercetin (10$100 \mathrm{mg} / \mathrm{kg}$, ip) $30 \mathrm{~min}$ before $\mathrm{KO}_{2}$ injection $(30 \mu \mathrm{g} / \mathrm{paw}$, ip/). Total counts of leukocytes, mononuclear cells, and neutrophils ( $6 \mathrm{~h}$ after stimulus injection), and antioxidant status (FRAP, ABTS, and GSH assays, $3 \mathrm{~h}$ after stimulus) were evaluated in animals pretreated with quercetin $(100 \mathrm{mg} / \mathrm{kg}, i p), 30 \mathrm{~min}$ before ip or ip/ injection of $\mathrm{KO}_{2}(30 \mu \mathrm{g} /$ cavity), respectively. Celecoxib: mice were treated with celecoxib (30 mg/kg, ip) $1 \mathrm{~h}$ before $\mathrm{KO}_{2}$ injection (30 $\mu \mathrm{g} / \mathrm{paw}$, $\mathrm{ipl}$ or $\mathrm{ip}$, and $1 \mathrm{mg} / \mathrm{mice})$, and the parameters evaluated were mechanical hyperalgesia, thermal hyperalgesia, paw flinches, paw licking, and the writhing response. Whether $\mathrm{KO}_{2}$ injection induced timedependent (0.5-7 h) COX-2 mRNA expression by qPCR was also determined. Results are reported as means \pm SE of measurements of 6 mice/group per experiment, and are representative of two separate experiments. It is noteworthy that different investigators prepared the solutions, administered them, and performed the testing procedures.

\section{Electronic pressure meter test}

Mechanical hyperalgesia was assessed as previously 
reported (11). In a quiet room, mice were placed in acrylic cages $(12 \times 10 \times 17 \mathrm{~cm})$ with wire grid floors, $30 \mathrm{~min}$ before testing. The test consisted of evoking a hind paw reflex with a hand-held force transducer (electronic anesthesiometer; Insight Equipamentos, Brazil) adapted with a $0.5 \mathrm{~mm}^{2}$ polypropylene tip. The investigator was trained to apply the tip perpendicularly to the central area of the hind paw with a gradual increase in pressure. The end point was characterized by the removal of the paw followed by clear flinching movements, and the intensity of pressure was recorded automatically. The animals were tested before (basal) and after treatment and stimuli, and the value for each interval was an average of 3 measurements. The results are reported as the change $(\Delta)$ in withdrawal threshold (in $\mathrm{g}$ ), calculated by subtracting the basal mean measurements from the mean measurements obtained at $0.5,1,3,5$, or $7 \mathrm{~h}$ after ipl injection of $\mathrm{KO}_{2}(3-100 \mu \mathrm{g} / \mathrm{paw})$. The dose of $\mathrm{KO}_{2}$ of $30 \mu \mathrm{g} /$ paw was selected for pharmacological testing.

\section{Hot plate test}

Mice were placed in a $10 \mathrm{~cm}$ wide glass cylinder on a hot plate (EFF 361, Insight Equipamentos) maintained at $55^{\circ} \mathrm{C}$. Two control latencies at least $10 \mathrm{~min}$ apart were determined for each mouse. The normal latency (reaction time) was $12-20 \mathrm{~s}$. The latency was also evaluated $0.5,1$, 3,5 , and $7 \mathrm{~h}$ after test compound administration. The reaction time was scored when the animal jumped or licked its paws. A maximum latency (cutoff) was set at $30 \mathrm{~s}$ to avoid tissue damage (12). A dose-response curve was performed using $\mathrm{KO}_{2}$ at doses of 3-100 $\mu \mathrm{g} /$ paw, and $30 \mu \mathrm{g} /$ paw was selected for pharmacological testing.

\section{Writhing response tests}

Each mouse was placed in a large glass cylinder and the intensity of nociceptive behavior was quantified by counting the total number of writhings (contraction of the abdominal muscle together with a stretching of hind limbs) occurring between 0 and 20 min after ip injection of $\mathrm{KO}_{2}$. The intensity of nociceptive behavior was expressed as the cumulative number of writhings over $20 \mathrm{~min}$. A doseresponse curve was performed using $\mathrm{KO}_{2}$ at doses of 30$1000 \mu \mathrm{g} /$ cavity (ip), and the dose of $1000 \mu \mathrm{g} /$ mouse was selected for pharmacological testing.

\section{Paw flinches and time spent licking test}

The number of paw flinches and time spent licking the stimulated paw were determined between 0 and 30 min after ip/ injection of $\mathrm{KO}_{2}$. Results are reported as the cumulative number of paw flinches and time spent licking the paw over $30 \mathrm{~min}$. A dose-response curve was performed using $\mathrm{KO}_{2}$ at doses of 1-30 $\mu \mathrm{g} / \mathrm{paw}$, and $30 \mu \mathrm{g} /$ paw was selected for pharmacological testing.

\section{Paw edema}

Paw edema was measured using an analog caliper
(Digmatic Caliper, Mitutoyo Corporation, Japan). Values of paw edema are reported as the difference between the paw thickness measured before (basal) and after induction of paw inflammation in millimeters. A dose-response curve was performed using $\mathrm{KO}_{2}$ at doses of $3-100 \mu \mathrm{g} /$ paw, and $30 \mu \mathrm{g} /$ paw was selected for pharmacological testing.

\section{Myeloperoxidase (MPO) activity}

The MPO kinetic-colorimetric assay was performed as described elsewhere (11) to verify leukocyte migration to the subcutaneous plantar tissue of the mouse hind paw. Seven hours after $\mathrm{KO}_{2}$ injection, the hind paw tissue of mice was collected and homogenized using TissueTearor (Biospec, USA), centrifuged at 16,100 $\mathrm{g}$ for $4 \mathrm{~min}$, and the resulting supernatant was assayed spectrophotometrically for MPO activity determination at $450 \mathrm{~nm}$ (Multi Scan Go Thermo Scientific, USA). The MPO activity of the samples was compared to a standard curve of neutrophils, and the results are reported as MPO activity (number of neutrophils $\times 10^{3} / \mathrm{mg}$ of tissue). A dose-response curve was performed using $\mathrm{KO}_{2}$ at doses of $3-100 \mu \mathrm{g} / \mathrm{paw}$, and $30 \mu \mathrm{g} /$ paw was selected for pharmacological testing.

\section{Leukocyte recruitment to the peritoneal cavity}

Peritoneal cavities were washed with $1 \mathrm{~mL}$ of phosphate-buffered saline (PBS) containing EDTA (37.2 mg/ $100 \mathrm{~mL}$ saline). Total leukocyte counts were performed in a Neubauer chamber after dilution in Turk's solution $(2 \%$ acetic acid, v/v), and differential cell counts were performed using the Fast Panoptic Kit for histological analysis (Laborclin, Brazil). Results are reported as number of cells per cavity $\left(\times 10^{6}\right)$. Leukocyte recruitment was determined $6 \mathrm{~h}$ after $\mathrm{KO}_{2}$ injection. Total and differential cell counts were both performed under a light microscope $(400 \times$ magnification, Olympus Optical Co., Germany) (12). A dose-response curve was calculated using $\mathrm{KO}_{2}$ at doses of $10-100 \mu \mathrm{g} /$ paw, and $30 \mu \mathrm{g} /$ paw was selected for pharmacological testing.

\section{FRAP and ABTS assays}

Paw skin samples were collected and immediately homogenized with $500 \mu \mathrm{L}$ of $1.15 \% \mathrm{KCl}$, and centrifuged $\left(10 \mathrm{~min} \times 200 \mathrm{~g} \times 4^{\circ} \mathrm{C}\right)$. The ability of a sample to resist oxidative damage was determined using FRAP and ABTS assays (13). For the FRAP assay, $50 \mu \mathrm{L}$ of supernatant was mixed with $150 \mu \mathrm{L}$ of deionized water and $1.5 \mathrm{~mL}$ of freshly prepared FRAP reagent. The reaction mixture was incubated at $37^{\circ} \mathrm{C}$ for 30 min and absorbance measured at $595 \mathrm{~nm}$. For the ABTS assay, the ABTS solution was diluted with PBS at $\mathrm{pH} 7.4$ at an absorbance of 0.80 at $730 \mathrm{~nm}$. Then $1.0 \mathrm{~mL}$ of diluted ABTS solution was mixed with $20 \mu \mathrm{L}$ of supernatant. After $6 \mathrm{~min}$, the absorbance was measured at $730 \mathrm{~nm}$. The results were equated against a Trolox standard curve (1.5-30 $\mu \mathrm{mol} / \mathrm{L}$, final 
concentrations). The results are reported as Trolox equivalents per milligram of tissue weight in both assays.

\section{GSH measurement}

Paw skin sample was collected and maintained at $-80^{\circ} \mathrm{C}$ for at least $48 \mathrm{~h}$, then the sample was homogenized with $200 \mu \mathrm{L}$ of $0.02 \mathrm{M}$ EDTA; the homogenate was mixed with $25 \mu \mathrm{L}$ of $50 \%$ trichloroacetic acid and homogenized three times for $15 \mathrm{~min}$. The mixture was then centrifuged $\left(15 \mathrm{~min} \times 1500 \mathrm{~g} \times 4^{\circ} \mathrm{C}\right)$ and the supernatant added to $200 \mu \mathrm{L}$ of $0.2 \mathrm{M}$ Tris buffer, $\mathrm{pH} 8.2$, and $10 \mu \mathrm{L}$ of $0.01 \mathrm{M}$ DTNB. After $5 \mathrm{~min}$, absorbance was measured at $412 \mathrm{~nm}$ against a blank reagent with no supernatant. A standard curve was calculated using standard GSH, and the results are reported as GSH per milligram protein (14). For protein determination, $60 \mu \mathrm{L}$ of supernatant were mixed with $60 \mu \mathrm{L}$ of freshly prepared copper reagent. After $10 \mathrm{~min}, 180 \mu \mathrm{L}$ of Folin solution was added. The resulting solution was incubated at $50^{\circ} \mathrm{C}$ for $10 \mathrm{~min}$, the absorbance was measured at $660 \mathrm{~nm}$, and the results were equated to a standard curve of bovine serum albumin.

\section{In vitro superoxide anion production assay}

An NBT reduction assay was carried out to evaluate the ability of $\mathrm{KO}_{2}$ to release superoxide anion at varied time points after its dilution in saline $(30 \mu \mathrm{g}, 25 \mu \mathrm{L})$. An equimolar solution of $\mathrm{KOH}$ diluted in saline was used as control. $\mathrm{KO}_{2}$ or $\mathrm{KOH}$ solutions were mixed with $100 \mu \mathrm{L}$ of NBT reagent $(1 \mathrm{mg} / \mathrm{mL})$ at the indicated time points after dissolution. After 15 min of incubation at room temperature, the supernatants were carefully removed. The formazan precipitates were solubilized by addition of $120 \mu \mathrm{L}$ of $\mathrm{KOH}(2 \mathrm{M})$ and $120 \mu \mathrm{L}$ of DMSO, and absorbance was read at $600 \mathrm{~nm}$ (15).

\section{qPCR}

Paw skin samples were homogenized in TRIzol reagent (Life Technologies, USA), and total RNA was isolated according to the manufacturer's instructions. RNA purity was confirmed by the $260 / 280$ ratio. RT-PCR and qPCR were performed using GoTaq 2-Step RT-qPCR System (Promega, USA) following the manufacturer's instructions. Complementary DNA was reversely transcribed from $2 \mathrm{mg}$ of total RNA, and qPCR was performed for 50 cycles on a LightCycler Nano Instrument (Roche, Switzerland). Primer sequences were as follows: Cox-2, forward: 5'-GTGGAAAAACCTCGTCCAGA-3', reverse: 5'-GCTCGGCTTCCAGTATTGAG-3'; and Gapdh, forward: 5'-CATACCAGGAAATGAGCTTG-3', reverse: 5'-ATGACATCAAGAAGGTGGTG-3'.

\section{Statistical analysis}

Results are reported as means \pm SE of measurements made on 6 mice/group per experiment and are representative of 2 separate experiments. Two-way analysis of variance (ANOVA) was used to compare the groups and doses at all times (curves). The analyzed factors were treatment, time, and time vs treatment interaction. When there was a significant time vs treatment interaction, oneway ANOVA followed by Tukey's $t$-test was performed for each time. On the other hand, when the nociceptive responses were presented as total values at the indicated time period, the differences between responses were evaluated by one-way ANOVA followed by Tukey's $t$-test. Statistical differences were considered to be significant at $\mathrm{P}<0.05$

\section{Results}

\section{Superoxide anion donor $\mathrm{KO}_{2}$ induced mechanical} hyperalgesia, thermal hyperalgesia, paw edema, and MPO activity

$\mathrm{KO}_{2}$ was administered $i p /$ at doses of 3-100 $\mu \mathrm{g} /$ paw in a final volume of $25 \mu \mathrm{L}$ of sterile saline. Mechanical hyperalgesia (Figure 1A), thermal hyperalgesia (Figure $1 \mathrm{~B}$ ), and paw edema (Figure $1 \mathrm{C}$ ) were evaluated $0.5-7 \mathrm{~h}$ after stimulus. All doses of $\mathrm{KO}_{2}$ induced statistically significant mechanical hyperalgesia compared to the control group (saline) at all time points, except the dose
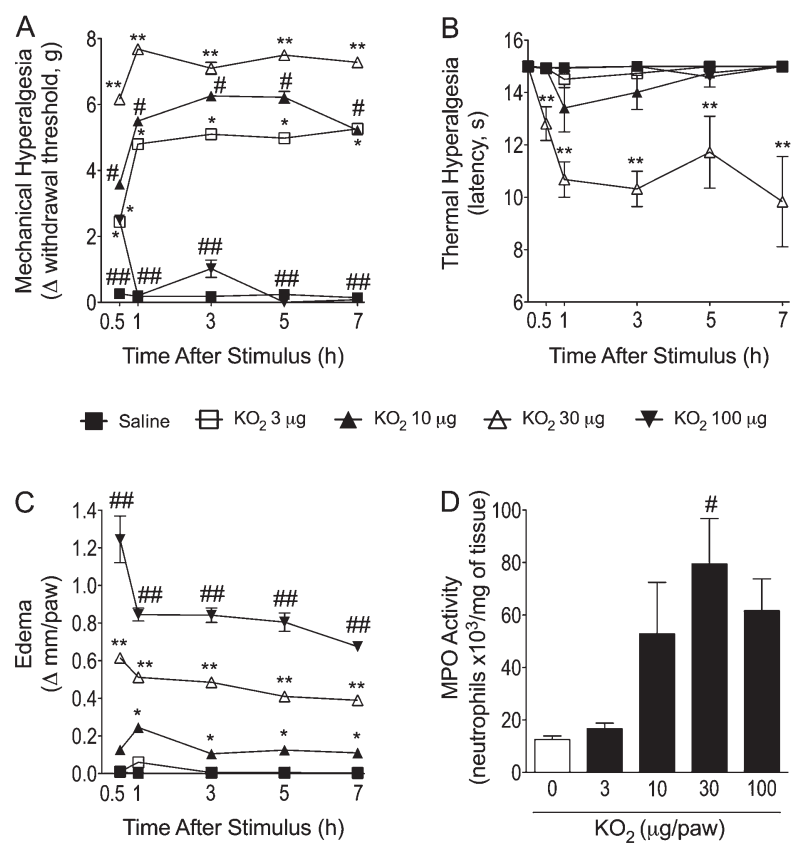

Figure 1. Intraplantar (ip/) injection of $\mathrm{KO}_{2}$ induced hyperalgesia, edema, and neutrophil recruitment. Mice received $\mathrm{KO}_{2}(3-100 \mu \mathrm{g}$, $25 \mu \mathrm{L}, i p /)$ or saline injection. The intensity of mechanical hyperalgesia $(A)$, thermal hyperalgesia $(B)$, and the paw edema (C) were measured 0.5-7 $\mathrm{h}$ after stimulus, and myeloperoxidase (MPO) activity at $7 \mathrm{~h}$. Data are reported as means \pm SE. * $\mathrm{P}<0.05$ vs saline control; ${ }^{\#} \mathrm{P}<0.05$ vs $3 \mu \mathrm{g}$; ${ }^{* *} \mathrm{P}<0.05$ vs $10 \mu \mathrm{g}$; ${ }^{\# \# \mathrm{P}<0.05}$ vs $30 \mu \mathrm{g}$ (one-way ANOVA followed by Tukey's $t$-test). 

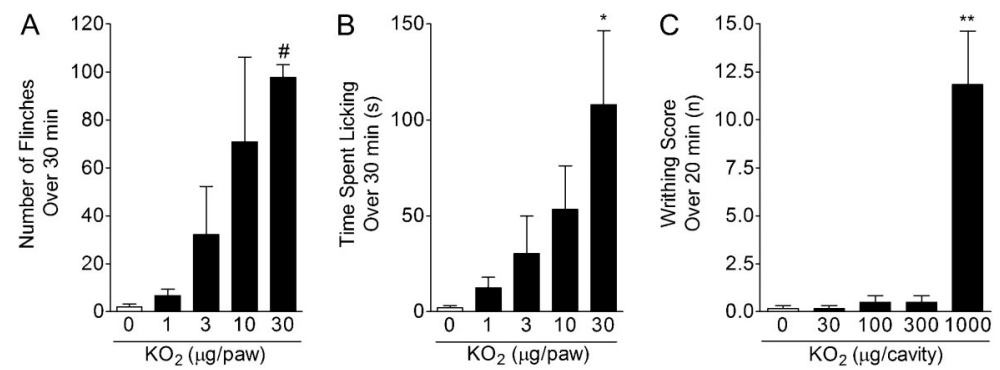

Figure 2. $\mathrm{KO}_{2}$ induced overt pain-like behavior. The number of paw flinches $(A)$, and the time spent licking the paw $(B)$ were evaluated during 30 min after $\mathrm{KO}_{2}(1-100 \mu \mathrm{g}$, ipl) or saline injection. The writhing score was evaluated $20 \mathrm{~min}$ after $\mathrm{KO}_{2}(30-1000 \mu \mathrm{g}$, ip) or saline injection. Data are reported as means $\pm \mathrm{SE}$. ${ }^{*} \mathrm{P}<0.05$ vs saline control; ${ }^{\#} \mathrm{P}<0.05$ vs $1 \mu \mathrm{g} ;{ }^{* *} \mathrm{P}<0.05$ vs $300 \mu \mathrm{g}$ (one-way ANOVA followed by Tukey's $t$ test).

of $100 \mu \mathrm{g} /$ paw (Figure $1 \mathrm{~A}$ ). $\mathrm{KO}_{2}$ at $30 \mu \mathrm{g} /$ paw induced statistically significant mechanical hyperalgesia compared to the other doses (Figure $1 \mathrm{~A}$ ). $\mathrm{KO}_{2}$ induced mechanical hyperalgesia in a bell-shaped curve, achieving the maximal effect with $30 \mu \mathrm{g} /$ paw and almost no mechanical hyperalgesia with $100 \mu \mathrm{g} /$ paw. Regarding thermal hyperalgesia, doses of 3,10 , and $100 \mu \mathrm{g} /$ paw of $\mathrm{KO}_{2}$ showed similar thresholds (Figure 1B). Only the dose of $30 \mu \mathrm{g} /$ paw induced a statistically significant reduction in thermal threshold when compared to the control group at all evaluated times (Figure $1 \mathrm{~B}$ ). $\mathrm{KO}_{2}$ induced a dosedependent increase in paw edema. $\mathrm{KO}_{2}$ did not induce paw edema at $3 \mu \mathrm{g} /$ paw, the dose of $10 \mu \mathrm{g} / \mathrm{paw}$ induced paw edema at 0.5 and $1 \mathrm{~h}$, and doses of 30 and $100 \mu \mathrm{g} /$ paw induced paw edema at all time points (Figure 1C). Only the dose of $30 \mu \mathrm{g} / \mathrm{paw}$ of $\mathrm{KO}_{2}$ induced a significant increase in MPO activity (Figure 1D).

\section{Superoxide anion induced dose-dependent pain-like behavior}

$\mathrm{KO}_{2}$ was administered at doses of $1-30 \mu \mathrm{g} /$ paw, and the number of flinches and the time spent licking the paw were quantified (Figure 2, A and $\mathrm{B}$ ). $\mathrm{KO}_{2}$ induced a dosedependent increase in the number of paw flinches and time spent licking the paw. Only the dose of $30 \mu \mathrm{g} / \mathrm{paw}$ induced statistically significant nociceptive responses compared to the vehicle control group. The writhing response was induced only by a dose of $1000 \mu \mathrm{g} /$ cavity of $\mathrm{KO}_{2}$ (Figure $2 \mathrm{C}$ ).

\section{Superoxide anion donor induced leukocyte recruitment}

$\mathrm{KO}_{2}(10-100 \mu \mathrm{g} /$ cavity) was injected ip and peritoneal exudates were collected after $6 \mathrm{~h}$, which is a standard time point for acute leukocyte recruitment to the peritoneal cavity (Figure 3A) (16). All doses induced significant increases in total leukocyte counts in a bell-shaped curve, with significant differences with the dose of $30 \mu \mathrm{g}$ compared to 10 and $100 \mu \mathrm{g}$ of $\mathrm{KO}_{2}$. A bell-shaped curve also resulted with counts for total mononuclear cells (Figure 3B) and neutrophils (Figure 3C). Again, the maximal effect was observed with the dose of $30 \mu \mathrm{g}$ of $\mathrm{KO}_{2}$, which was selected for the leukocyte recruitment experiments in this study.

\section{$\mathrm{KO}_{2}$ in saline presented time-dependent decay of superoxide anion levels}

An important point to be determined was whether $\mathrm{KO}_{2}$ saline solution would present detectable superoxide anion, which was tested with $\mathrm{KO}_{2}$ solution at $30 \mu \mathrm{g} /$ $25 \mu \mathrm{L}$, a concentration selected on the basis of the results of Figures 1-3. Saline solution did not reduce NBT, indicating that there was no detectable superoxide anion (Figure 4). $\mathrm{KO}_{2}$ saline solution presented significant NBT reduction activity, indicating detectable superoxide anion levels at 1 and 5 min after solution preparation. Ten minutes after $\mathrm{KO}_{2}$ saline solution preparation, all NBT reducing activity vanished, indicating that no superoxide anions were present. A $\mathrm{KOH}$ saline solution at an equimolar concentration of the $\mathrm{KO}_{2}$ solution was tested
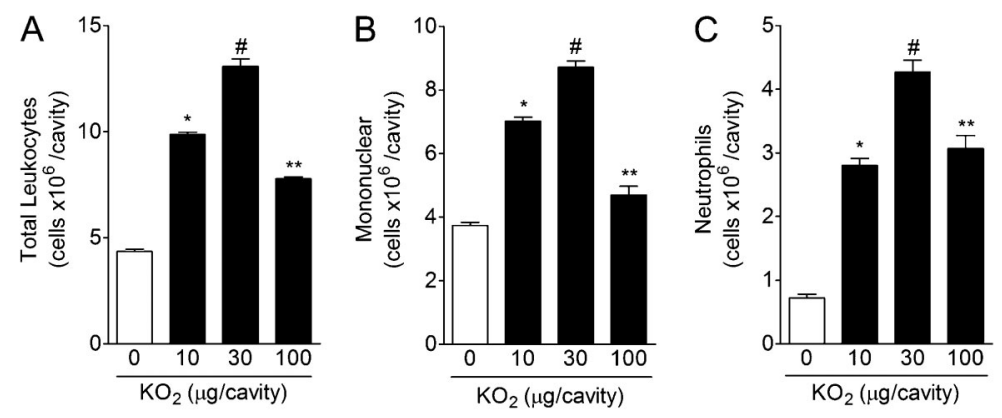

Figure 3. $\mathrm{KO}_{2}$ induced leukocyte recruitment to the peritoneal cavity. The peritoneal cells were harvested $6 \mathrm{~h}$ after $\mathrm{KO}_{2}(10-100 \mu \mathrm{g}$, ip) or saline injection. Total $(A)$ and differential $(B$ and $C)$ cell counts were determined. Data are reported as means \pm SE. * $P<0.05$ vs saline control; ${ }^{\#} \mathrm{P}<0.05$ vs $10 \mu \mathrm{g} ;{ }^{* *} \mathrm{P}<0.05$ vs $30 \mu \mathrm{g}$ (one-way ANOVA followed by Tukey's $t$-test). 


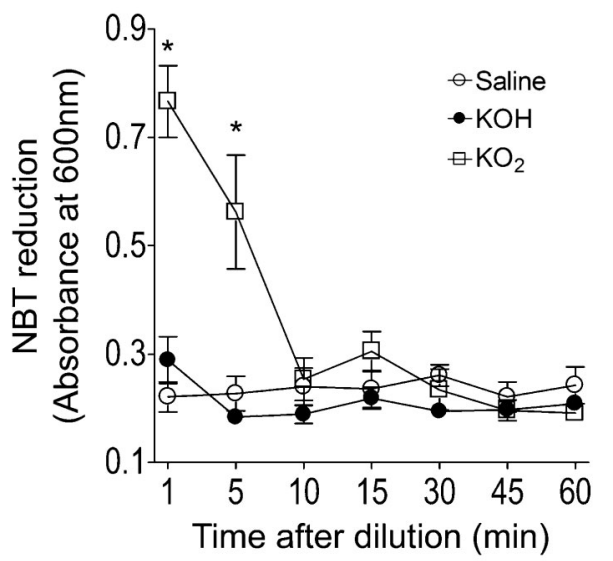

Figure 4. $\mathrm{KO}_{2}$ dissolution in saline produced superoxide anion. $\mathrm{KO}_{2}(30 \mu \mathrm{g}, 25 \mu \mathrm{L}$ of saline) or $\mathrm{KOH}$ (equimolar concentration to $\mathrm{KO}_{2}, 25 \mu \mathrm{L}$ of saline) solutions were prepared and mixed with $100 \mu \mathrm{L}$ of nitrobluetetrazolium (NBT) reagent at the indicated time points. Data are reported as means $\pm S E .{ }^{*} \mathrm{P}<0.05$ vs saline control and $\mathrm{KOH}$ solution (one-way ANOVA followed by Tukey's $t$-test).

as control. The $\mathrm{KOH}$ saline solution did not present detectable superoxide anion levels (Figure 4). These results demonstrated that $\mathrm{KO}_{2}$ saline solution injected up to $5 \mathrm{~min}$ after its preparation presents significant amounts of superoxide anion, while the procedure for its injection into one group of mice takes approximately $3 \mathrm{~min}$. Therefore, these data confirmed the successful administration of superoxide anion.

\section{$\mathrm{KO}_{2}$-induced hyperalgesia and pain-like behavior were inhibited by morphine treatment}

Mice received $30 \mu \mathrm{g} /$ paw of $\mathrm{KO}_{2}$ and after $2 \mathrm{~h}$ were treated with morphine (opioid, 2-12 $\mu \mathrm{g} / \mathrm{paw}$ ) and, after an additional $1 \mathrm{~h}$, mechanical (Figure 5A) and thermal (Figure 5B) hyperalgesia were evaluated. The dose of $2 \mu \mathrm{g}$ morphine did not alter $\mathrm{KO}_{2}$-induced mechanical hyperalgesia, while $6 \mu \mathrm{g}$ morphine reduced mechanical hyperalgesia compared to the control group, and $12 \mu \mathrm{g}$ morphine reduced mechanical hyperalgesia compared to all lower doses (Figure 5A). Morphine was also effective in reducing $\mathrm{KO}_{2}$-induced thermal hyperalgesia at a dose of $12 \mu \mathrm{g}$ (Figure 5B). Naloxone $(1 \mathrm{mg} / \mathrm{kg}$, ip, $30 \mathrm{~min}$ before morphine treatment) prevented the analgesic effect of morphine over $\mathrm{KO}_{2}$-induced mechanical (Figure $5 \mathrm{~A}$ ) and thermal (Figure 5B) hyperalgesia. Morphine at a dose of $12 \mu \mathrm{g} /$ paw (cotreatment) also inhibited $\mathrm{KO}_{2}$ induced paw flinching (Figure 5C) and licking (Figure 5D) behaviors, and, again, naloxone treatment prevented the analgesic effect of morphine.

The standard antioxidant flavonoid, quercetin, inhibited $\mathrm{KO}_{2}$-induced mechanical hyperalgesia, thermal hyperalgesia, and edema

Mice were treated with quercetin $(10-100 \mathrm{mg} / \mathrm{kg}$, ip)
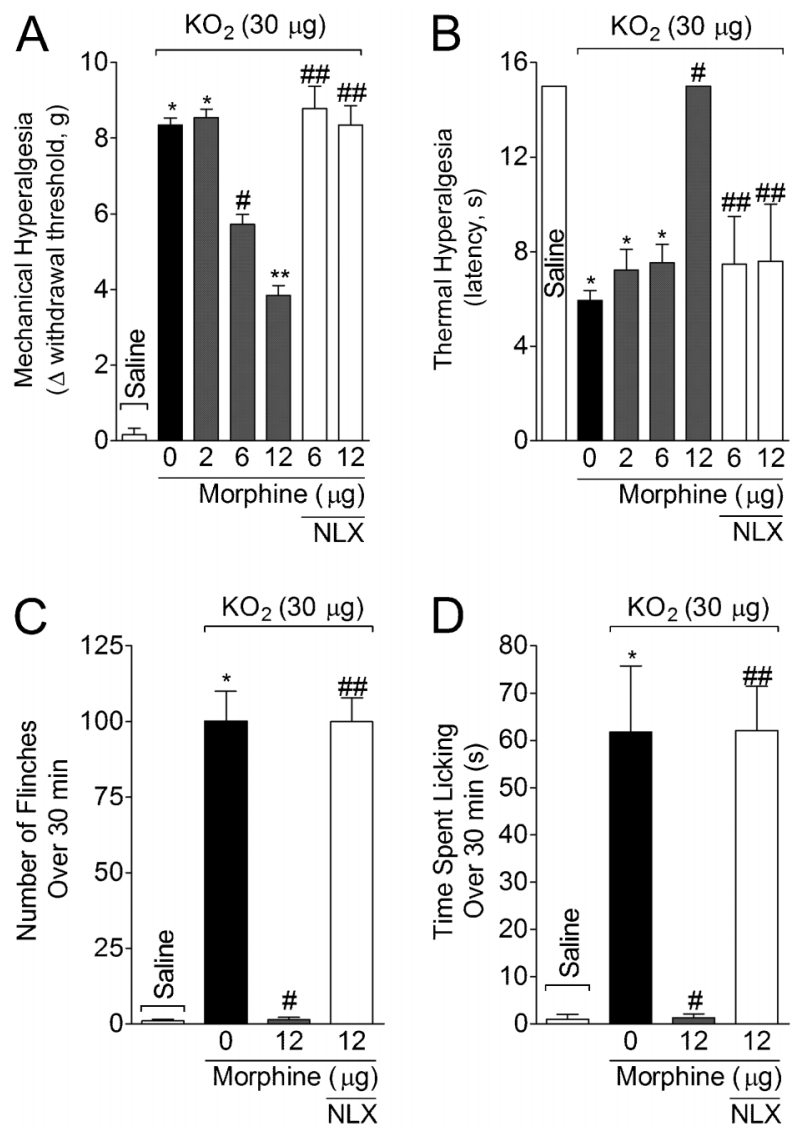

Figure 5. Morphine inhibited $\mathrm{KO}_{2}$-induced hyperalgesia and overt pain-like behavior in a naloxone-sensitive manner. Mice were post-treated $(A$ and $B)$ with morphine $(2-12 \mu \mathrm{g}$, ip/) or vehicle (saline) $45 \mathrm{~min}$ before the measurements. The nociceptive thresholds to mechanical $(A)$ and thermal $(B)$ stimuli were measured $3 \mathrm{~h}$ after $\mathrm{KO}_{2}(30 \mu \mathrm{g} /$ paw $)$ injection. In another set of experiments, mice were pre-treated $(C$ and $D)$ with morphine $(12 \mu \mathrm{g}, i p /)$ or vehicle (saline) $45 \mathrm{~min}$ before $\mathrm{KO}_{2}(30 \mu \mathrm{g} / \mathrm{paw})$ or saline injection. The number of paw flinches $(C)$, and the time spent licking the paw $(D)$ were measured during $30 \mathrm{~min}$. Treatment with naloxone is indicated as NLX $(1 \mathrm{mg} / \mathrm{kg}$, ip, $30 \mathrm{~min}$ before morphine injection). Data are reported as means \pm SE. ${ }^{*} \mathrm{P}<0.05$ vs saline control; ${ }^{\#} \mathrm{P}<0.05$ vs $\mathrm{KO}_{2}$ control (black bars); ${ }^{*} \mathrm{P}<0.05$ vs $6 \mu \mathrm{g}$ morphine; ${ }^{\# \#} \mathrm{P}<0.05$ vs $12 \mu \mathrm{g}$ morphine (one-way ANOVA followed by Tukey's $t$-test).

$1 \mathrm{~h}$ before ipl injection of $\mathrm{KO}_{2}$ (Figure 6). Quercetin inhibited $\mathrm{KO}_{2}$-induced mechanical hyperalgesia (Figure $6 \mathrm{~A}$ ), thermal hyperalgesia (Figure 6B), and paw edema (Figure 6C) in a dose-dependent manner. Thus, the dose of $100 \mathrm{mg} / \mathrm{kg}$ quercetin was selected for the experiments presented in Figures 7-9.

\section{Quercetin inhibited $\mathrm{KO}_{2}$-induced overt pain-like behavior, leukocyte recruitment to the peritoneal cavity, and oxidative stress}

Quercetin inhibited $\mathrm{KO}_{2}$-induced overt pain-like behaviors 

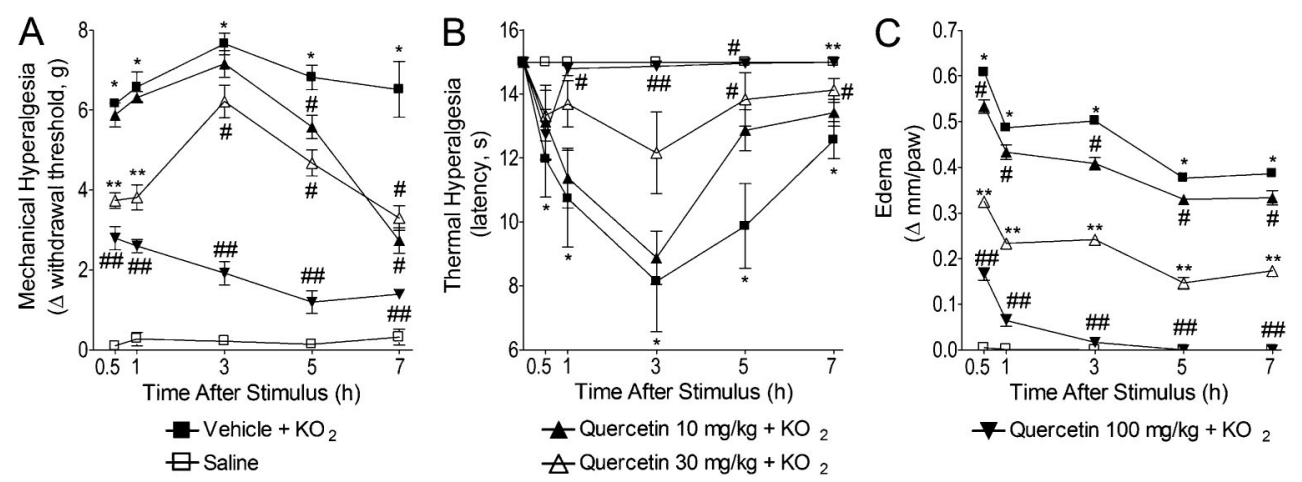

Figure 6. Quercetin inhibited the $\mathrm{KO}_{2}$-induced mechanical hyperalgesia $(A)$, thermal hyperalgesia $(B)$, and edema $(C)$ in a dosedependent manner. Mice were treated with quercetin $\left(10-100 \mathrm{mg} / \mathrm{kg}\right.$, ip) or vehicle (20\% tween 80 in saline, $150 \mu \mathrm{L}$, ip) $1 \mathrm{~h}$ before $\mathrm{KO}_{2}$ $(30 \mu \mathrm{g} / \mathrm{paw})$ or saline injection. Data are reported as means $\pm \mathrm{SE}$. ${ }^{*} \mathrm{P}<0.05$ vs saline control; ${ }^{*} \mathrm{P}<0.05$ vs $\mathrm{KO}_{2}$ control; ${ }^{* *} \mathrm{P}<0.05$ vs $10 \mathrm{mg} / \mathrm{kg}$; \#\# $\mathrm{P}<0.05$ vs $30 \mathrm{mg} / \mathrm{kg}$ (one-way ANOVA followed by Tukey's $t$-test).

of paw flinching (Figure 7A), paw licking (Figure 7B), and abdominal writhing (Figure 7C). Quercetin also inhibited $\mathrm{KO}_{2}$-induced recruitment of total leukocytes (Figure 8A), mononuclear cells (Figure 8B), and neutrophils (Figure $8 \mathrm{C}$ ) to the peritoneal cavity of the mice. The ipl injection of $\mathrm{KO}_{2}$ induced diminished ABTS (Figure 9A), FRAP (Figure 9B), and GSH levels (Figure $9 \mathrm{C}$ ) in plantar skin samples. Quercetin inhibited a $\mathrm{KO}_{2}-$ induced decrease in ABTS (Figure 9A), as well as FRAP (Figure 9B) and GSH levels.

\section{The COX-2 selective inhibitor, celecoxib, inhibited $\mathrm{KO}_{2}$-induced nociception and COX-2 mRNA expression}

Mice were treated with celecoxib $(30 \mathrm{mg} / \mathrm{kg}$, ip) (17) $1 \mathrm{~h}$ before $\mathrm{ipl}(30 \mu \mathrm{g} / \mathrm{paw})$ or ip $(1 \mathrm{mg} / \mathrm{mice})$ injection of $\mathrm{KO}_{2}$ (Figure 10). Celecoxib inhibited $\mathrm{KO}_{2}$-induced mechanical hyperalgesia (Figure 10A), thermal hyperalgesia (Figure 10B), paw flinching (Figure 10C), paw licking (Figure 10D), abdominal writhing (Figure 10E), and COX-2 mRNA expression in paw skin samples (Figure 10F). Therefore, $\mathrm{KO}_{2}$-induced nociception depends on COX-2.

\section{Discussion}

Superoxide anion has been established as an important mediator of pain and inflammation (6-9). Most of the evidence in this regard targeted superoxide anion metabolism to evaluate its inflammatory and nociceptive effects. An important approach to study the effects of superoxide anion would be to inject a superoxide anion donor such as $\mathrm{KO}_{2} . \mathrm{KO}_{2}$ injection induces thermal hyperalgesia in the Hargreaves test $(7,10)$. In the present study, we provided evidence for the induction of varied nociceptive and inflammatory responses in mice by administering $\mathrm{KO}_{2}$. The $\mathrm{KO}_{2}$-induced nociceptive behaviors were responsive to treatment with the opioid receptor agonist, morphine, and COX-2 selective inhibitor, celecoxib $(18,19)$. Furthermore, an antioxidant with analgesic and antiinflammatory effects, quercetin $(2,4)$, inhibited $\mathrm{KO}_{2}-$ induced pain, inflammation, and oxidative stress.

$\mathrm{KO}_{2}$ has been used as a generator of superoxide anion in vivo $(7,10)$. Superoxide anion is generated in normal aerobic metabolism by one-electron transfer to molecular oxygen (20), as well as by NADPH oxidase during inflammation in vivo (21). Superoxide anion is a
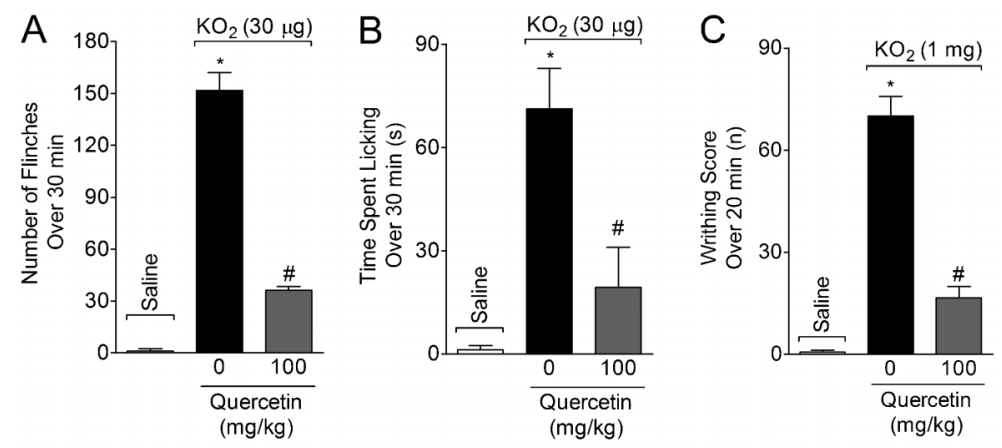

Figure 7. Quercetin inhibited the $\mathrm{KO}_{2}$-induced overt pain-like behaviors. Mice were treated with quercetin $(100 \mathrm{mg} / \mathrm{kg}, i p)$ or vehicle $1 \mathrm{~h}$ before stimuli. The number of paw flinches $(A)$, and the time spent licking the paw $(B)$ were quantified during $30 \mathrm{~min}$ after $\mathrm{KO}_{2}(30 \mu \mathrm{g} / \mathrm{paw})$ injection. The writhing score $(C)$ was quantified during 20 min after $\mathrm{KO}_{2}(1 \mathrm{mg}$, ip) injection. Data are reported as means $\pm \mathrm{SE}$. ${ }^{*} \mathrm{P}<0.05$ vs saline control; ${ }^{\#} \mathrm{P}<0.05$ vs $\mathrm{KO}_{2}$ control (one-way ANOVA followed by Tukey's $t$-test). 

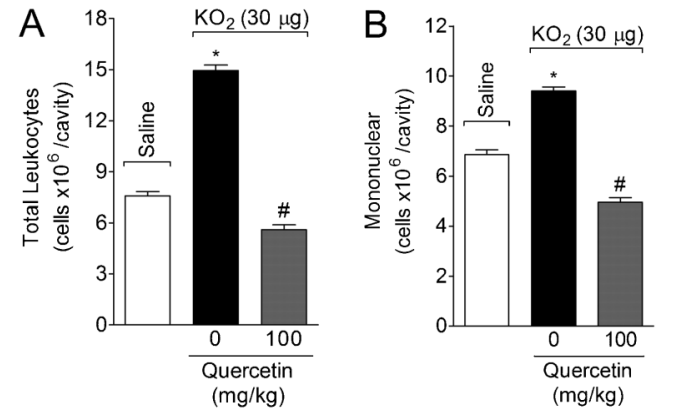

Figure 8. Quercetin inhibited the $\mathrm{KO}_{2}$-induced leukocyte recruitment. Mice were treated with quercetin $(100 \mathrm{mg} / \mathrm{kg}, i p)$ or vehicle $1 \mathrm{~h}$ before $\mathrm{KO}_{2}(30 \mu \mathrm{g}, i p)$ injection. The total number of leukocytes $(A)$, mononuclear cells $(B)$, and neutrophils $(C)$ were determined $6 \mathrm{~h}$ after stimulus. Data are reported as means $\pm S E$. ${ }^{*} \mathrm{P}<0.05$ vs saline control; ${ }^{\#} \mathrm{P}<0.05$ vs $\mathrm{KO}_{2}$ control (oneway ANOVA followed by Tukey's $t$-test). precursor of additional ROS with enhanced toxicity, including hydroxyl radical, hypochlorous acid, and singlet oxygen (22). Nevertheless, the actions of superoxide anion are not solely related to deleterious effects, but rather it is also a signaling molecule. For instance, neuropathy- and inflammation-induced superoxide anion activate p38 mitogen-activated protein (MAP) kinase, which in turn activates the transcription factor $N F \kappa B$, and JNK and ERK MAP kinases, which activate activating protein-1 (AP-1). NF $\kappa$ B and AP-1 increase the expression of pro-inflammatory molecules $(1,10,23)$.

$\mathrm{KO}_{2}$ injection is a simple procedure that can be reproduced in any laboratory, making it easy to access the mechanisms triggered by increased superoxide anion levels. It is essential to inject $\mathrm{KO}_{2}$ solution up to $5 \mathrm{~min}$ after its preparation, since the levels of superoxide anion decay rapidly in aqueous solution. $\mathrm{KO}_{2}$ induced pronounced inflammatory and nociceptive responses irrespective of the administration foci. Therefore, its action is not restricted to one tissue. This model of superoxide anion-dependent inflammation and pain exhibited dose-dependent effects, except in abdominal writhing behavior in which only the higher dose tested was capable of inducing this behavior. Moreover, the dose of $\mathrm{KO}_{2}$ of $100 \mu \mathrm{g} / \mathrm{paw}$ did not induce further increases in mechanical and thermal hyperalgesia compared to the dose of $30 \mu \mathrm{g} / \mathrm{paw}$. It is possible that $100 \mu \mathrm{g} / \mathrm{paw}$ induced an exaggerated inflammatory response. This condition is similar to sepsis, in which there is paralysis of neutrophil recruitment when the primary infectious foci are not under control and overt inflammation and infection become systemic (24). Accordingly, $100 \mu \mathrm{g} /$ paw of $\mathrm{KO}_{2}$ induced equal or even lower responses compared to $10 \mu \mathrm{g} /$ paw with respect to MPO activity, total leukocytes, mononuclear cells, and neutrophil recruitment, while $30 \mu \mathrm{g} /$ paw induced significant responses compared to 10 and $100 \mu \mathrm{g} /$ paw. Considering that recruited neutrophils contribute to hyperalgesia (25-27), it is likely that reduced leukocyte recruitment with $100 \mu \mathrm{g}$ compared to $30 \mu \mathrm{g}$ of $\mathrm{KO}_{2}$ also helps explain why $100 \mu \mathrm{g}$ did not induce further increases in nociception. Another important feature of the model is its susceptibility to pre- and post-treatment, as observed for quercetin and celecoxib, and morphine, respectively.

In addition to $\mathrm{KO}_{2}$ injection $(7,10)$, previous models of ROS-induced inflammation and pain include inhibitors of hyperalgesia induced by mitochondrial electron transport complexes I (rotenone) and III (antimycin) (28), administration of the ROS donor tert-butyl hydroperoxide-induced hyperalgesia (29), and peroxynitrite-induced enhancement of carrageenan-induced paw edema and thermal hyperalgesia (8). The emerging literature demonstrated that modulation of superoxide anion using SOD mimetics (M40403, TEMPOL) and peroxynitrite levels using the peroxynitrite decomposition catalyst [FeTM-4-PyP $(5+)$ ] reduce inflammatory mechanical hyperalgesia (23), thermal hyperalgesia $(7,8,10,30)$, paw flinching, paw licking (31), paw edema $(8,10)$, and leukocyte recruitment $(21)$. To our knowledge, this is the first study to demonstrate that superoxide anion donor $\mathrm{KO}_{2}$ induces mechanical
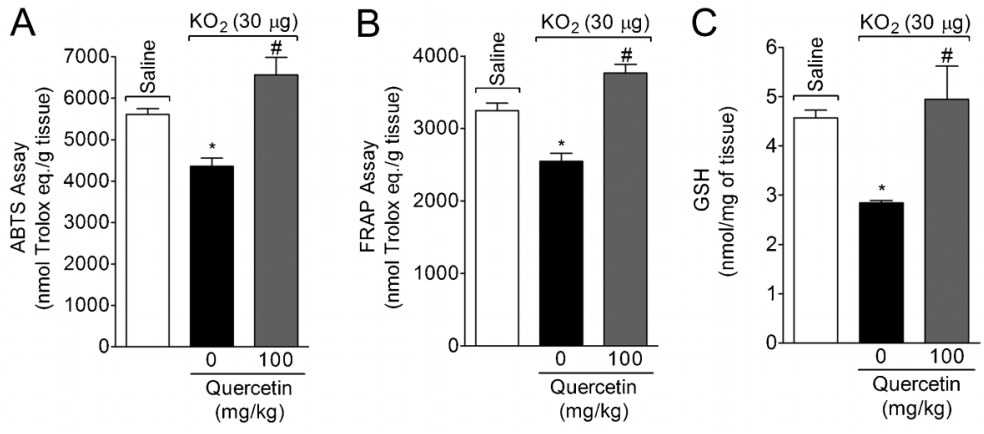

Figure 9. Quercetin inhibited $\mathrm{KO}_{2}$-induced oxidative stress. Mice were treated with quercetin $\left(100 \mathrm{mg} / \mathrm{kg}\right.$, ip) or vehicle $1 \mathrm{~h}$ before $\mathrm{KO}_{2}$ $(30 \mu \mathrm{g} / \mathrm{paw})$ injection. The antioxidant capacity was measured by $\operatorname{ABTS}(A), \operatorname{FRAP}(B)$, and GSH $(C)$ assays, $3 \mathrm{~h}$ after stimulus injection. ABTS: free-radical scavenging ability; FRAP: ferric-reducing ability potential; GSH: glutathione. Data are reported as means $\pm \mathrm{SE}$. ${ }^{*} \mathrm{P}<0.05$ vs saline control; ${ }^{\#} \mathrm{P}<0.05$ vs $\mathrm{KO}_{2}$ control (one-way ANOVA followed by Tukey's $t-$ test). 

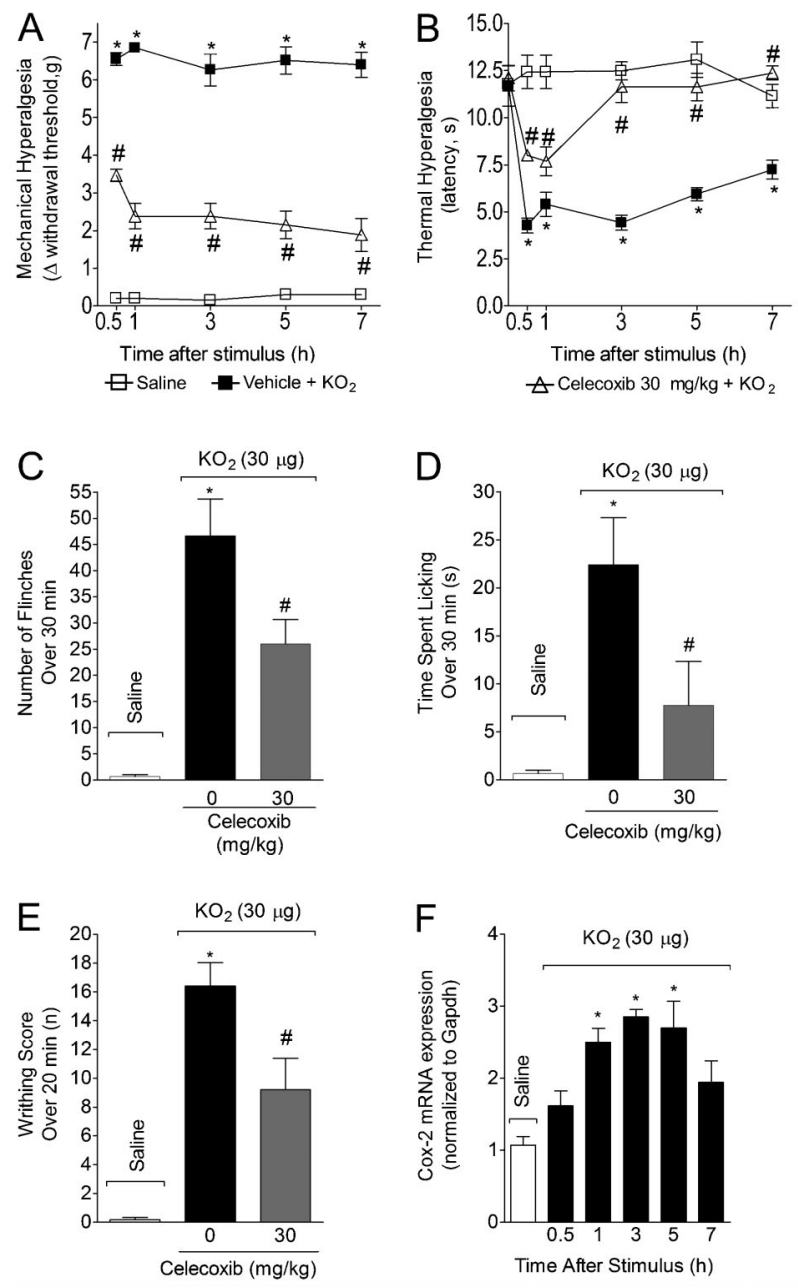

Figure 10. $\mathrm{KO}_{2}$ induced $\mathrm{COX}$-2-dependent nociception. Mice were treated with celecoxib $(30 \mathrm{mg} / \mathrm{kg}$, ip) or vehicle (saline) $1 \mathrm{~h}$ before $i p l(30 \mu \mathrm{g}, 25 \mu \mathrm{L})$ or ip $\left(1 \mathrm{mg} /\right.$ mice) injection of $\mathrm{KO}_{2}$. The intensity of mechanical hyperalgesia $(A)$ and thermal hyperalgesia $(B)$ were measured $0.5-7 \mathrm{~h}$ after stimulus, paw flinching $(C)$ and licking $(D)$ were evaluated during $30 \mathrm{~min}$, and writhing response was evaluated during $20 \mathrm{~min}(E)$. COX-2 mRNA expression $(F)$ was evaluated by qPCR 0.5-7 $\mathrm{h}$ after ip/ injection of $\mathrm{KO}_{2}$. Data are reported as means $\pm \mathrm{SE}$. ${ }^{*} \mathrm{P}<0.05$ vs saline control; \# $\mathrm{P}<0.05$ vs vehicle control $(0 \mathrm{mg} / \mathrm{kg}$ ) (one-way ANOVA followed by Tukey's $t$-test).

hyperalgesia, thermal hyperalgesia in the hot plate test, paw edema, paw licking, abdominal writhing, and neutrophil recruitment. In agreement with the role of ROS in these responses and the present data, antioxidants such as quercetin inhibit carrageenan-induced mechanical hyperalgesia, thermal hyperalgesia in the hot plate test and paw edema, formalin-induced paw licking and flinching, acetic acid- and phenyl-p-benzoquinoneinduced abdominal contortions, and carrageenan-induced MPO activity in paw skin, as well as neutrophil recruitment to the abdominal cavity $(2,5,6)$. These data also justify the selection of quercetin in the present study. Quercetin is able to directly scavenge superoxide anion (32), as well as inhibit COX-2 mRNA expression and prostaglandin $E_{2}$ production (33). Therefore, this study did not exclude the possibility that quercetin could be acting by inhibiting COX-2 mRNA expression and prostaglandin $E_{2}$ production, in addition to its antioxidant effect.

Excessive superoxide anion production has been attributed to inhibition of mitochondrial manganese SOD (MnSOD), an enzyme that controls the levels of superoxide anion. Superoxide anion reacts with nitric oxide to generate peroxynitrite that, in turn, inactivates MnSOD by nitration of Tyr-34 in a manganese-catalyzed process. This is known as a "feed-forward" mechanism that allows further accumulation of superoxide anion and peroxynitrite (9). Despite the hypothesis that peroxynitrite mediates superoxide anion-induced hyperalgesia, there is evidence that nitric oxide and superoxide anion may operate independently of each other to induce pain (34).

Intrathecal administration of tert-butyl hydroperoxide (a ROS donor) increases the frequency and amplitude of spontaneous excitatory postsynaptic currents in neurons, which was inhibited by antagonists of non-N-methyl-Daspartate glutamate, TRPA1 and TRPV1 receptors. These results indicate a neuronal effect of ROS by inducing glutamate release and TRPA1 and TRPV1 activity (29). Thus, ROS may act as neuronal activators, which lines up well with the immediate nociceptive responses observed by injection of $\mathrm{KO}_{2}$, such as paw flinching, paw licking, and abdominal contortions. On the other hand, superoxide anion (from pyrogallol) and hydroxyl radical (from Fe-EDTA in hydrogen peroxide) did not induce ongoing activity or nociceptor sensitization to heat and mechanical stimuli (35), arguing against a direct neuronal effect of ROS. Considering that the effects of $\mathrm{KO}_{2}$ include the induction of leukocyte recruiment, which depends on activation of tissue resident cells, the present data corroborate that ROS may trigger direct and indirect neuronal events $(29,35)$.

In conclusion, the present data add to the literature regarding the inflammatory and nociceptive roles of superoxide anion and ROS, and demonstrate that $\mathrm{KO}_{2}$ is a useful tool to trigger a great variety of superoxide anion-dependent inflammatory and nociceptive responses, which include thermal hyperalgesia in the Hargreaves test (7), mechanical hyperalgesia, thermal hyperalgesia in the hot plate test, paw edema, paw licking, paw flinching, abdominal writhing, and neutrophil recruitment (present data).

\section{Acknowledgments}

Research supported by CNPq, CAPES, Ministério da Ciência Tecnologia e Inovação (MCTI), Secretaria da Ciência, Tecnologia e Ensino Superior (SETI), Fundação Araucária, and Paraná State Government. 


\section{References}

1. Verri WA Jr, Vicentini FTMC, Baracat MM, Georgetti SR, Cardoso RDR, Cunha TM, et al. Flavonoids as antiinflammatory and analgesic drugs: mechanisms of action and perspectives in the development of pharmaceutical forms. In: Rahman AU (Editor), Studies in natural products chemistry. 1st edn. Amsterdam: Elsevier; 2012. p 297-330.

2. Valerio DA, Georgetti SR, Magro DA, Casagrande R, Cunha TM, Vicentini FT, et al. Quercetin reduces inflammatory pain: inhibition of oxidative stress and cytokine production. J Nat Prod 2009; 72: 1975-1979, doi: 10.1021/np900259y.

3. Souto FO, Zarpelon AC, Staurengo-Ferrari L, Fattori V, Casagrande R, Fonseca MJ, et al. Quercetin reduces neutrophil recruitment induced by CXCL8, LTB4, and fMLP: inhibition of actin polymerization. J Nat Prod 2011; 74: 113118, doi: $10.1021 / \mathrm{np} 1003017$.

4. Guazelli CF, Fattori V, Colombo BB, Georgetti SR, Vicentini FT, Casagrande R, et al. Quercetin-loaded microcapsules ameliorate experimental colitis in mice by anti-inflammatory and antioxidant mechanisms. J Nat Prod 2013; 76: 200-208, doi: 10.1021/np300670w.

5. Borghi SM, Carvalho TT, Staurengo-Ferrari L, Hohmann MS, Pinge-Filho $P$, Casagrande $R$, et al. Vitexin inhibits inflammatory pain in mice by targeting TRPV1, oxidative stress, and cytokines. J Nat Prod 2013; 76: 1141-1149, doi: 10.1021/np400222v.

6. Navarro SA, Serafim KG, Mizokami SS, Hohmann MS, Casagrande R, Verri WA Jr. Analgesic activity of piracetam: effect on cytokine production and oxidative stress. Pharmacol Biochem Behav 2013; 105: 183-192, doi: 10.1016/j.pbb.2013.02.018.

7. Wang ZQ, Porreca F, Cuzzocrea S, Galen K, Lightfoot R, Masini $E$, et al. A newly identified role for superoxide in inflammatory pain. J Pharmacol Exp Ther 2004; 309: 869878, doi: 10.1124/jpet.103.064154.

8. Khattab MM. TEMPOL, a membrane-permeable radical scavenger, attenuates peroxynitrite- and superoxide anionenhanced carrageenan-induced paw edema and hyperalgesia: a key role for superoxide anion. Eur J Pharmacol 2006; 548: 167-173, doi: 10.1016/j.ejphar.2006.08.007.

9. Salvemini D, Little JW, Doyle T, Neumann WL. Roles of reactive oxygen and nitrogen species in pain. Free Radic Biol Med 2011; 51: 951-966, doi: 10.1016/j.freeradbiomed. 2011.01.026.

10. Ndengele MM, Cuzzocrea S, Esposito E, Mazzon E, Di Paola R, Matuschak GM, et al. Cyclooxygenases 1 and 2 contribute to peroxynitrite-mediated inflammatory pain hypersensitivity. FASEB J 2008; 22: 3154-3164, doi: 10.1096/fj.08-108159.

11. Casagrande R, Georgetti SR, Verri WA Jr, Dorta DJ, dos Santos AC, Fonseca MJ. Protective effect of topical formulations containing quercetin against UVB-induced oxidative stress in hairless mice. J Photochem Photobiol B 2006; 84: 21-27, doi: 10.1016/j.jphotobiol.2006.01.006.

12. Verri WA Jr, Souto FO, Vieira SM, Almeida SC, Fukada SY, $\mathrm{Xu} \mathrm{D}$, et al. IL-33 induces neutrophil migration in rheumatoid arthritis and is a target of anti-TNF therapy. Ann Rheum Dis 2010; 69: 1697-1703, doi: 10.1136/ard.2009.122655.

13. Katalinic V, Modun D, Music I, Boban M. Gender differences in antioxidant capacity of rat tissues determined by $2,2^{\prime}-$ azinobis (3-ethylbenzothiazoline 6-sulfonate; ABTS) and ferric reducing antioxidant power (FRAP) assays. Comp Biochem Physiol C Toxicol Pharmacol 2005; 140: 47-52, doi: 10.1016/j.cca.2005.01.005.

14. Sedlak J, Lindsay RH. Estimation of total, protein-bound, and nonprotein sulfhydryl groups in tissue with Ellman's reagent. Anal Biochem 1968; 25: 192-205, doi: 10.1016/ 0003-2697(68)90092-4.

15. Wang HD, Pagano PJ, Du Y, Cayatte AJ, Quinn MT, Brecher $P$, et al. Superoxide anion from the adventitia of the rat thoracic aorta inactivates nitric oxide. Circ Res 1998; 82 810-818, doi: 10.1161/01.RES.82.7.810.

16. Verri WA Jr, Cunha TM, Ferreira SH, Wei X, Leung BP, Fraser A, et al. IL-15 mediates antigen-induced neutrophil migration by triggering IL-18 production. Eur J Immunol 2007; 37: 3373-3380, doi: 10.1002/eji.200737488.

17. Sun YH, Dong YL, Wang YT, Zhao GL, Lu GJ, Yang J, et al. Synergistic analgesia of duloxetine and celecoxib in the mouse formalin test: a combination analysis. PLOS One 2013; 8: e76603, doi: 10.1371/journal.pone.0076603.

18. Carvalho TT, Flauzino T, Otaguiri ES, Batistela AP, Zarpelon AC, Cunha TM, et al. Granulocyte-colony stimulating factor (G-CSF) induces mechanical hyperalgesia via spinal activation of MAP kinases and PI3K in mice. Pharmacol Biochem Behav 2011; 98: 188-195, doi: 10.1016/j.pbb.2010.12.027.

19. Rezende RM, Paiva-Lima P, Dos Reis WG, Camelo VM, Bakhle YS, de Francischi JN. Celecoxib induces tolerance in a model of peripheral inflammatory pain in rats. Neuropharmacology 2010; 59: 551-557, doi: 10.1016/ j.neuropharm.2010.07.022.

20. Fridovich I. The biology of oxygen radicals. Science 1978; 201: 875-880, doi: 10.1126/science.210504

21. Hattori H, Subramanian KK, Sakai J, Jia Y, Li Y, Porter TF, et al. Small-molecule screen identifies reactive oxygen species as key regulators of neutrophil chemotaxis. Proc Natl Acad Sci U S A 2010; 107: 3546-3551, doi: 10.1073/ pnas.0914351107.

22. Taubert D, Breitenbach T, Lazar A, Censarek P, Harlfinger $\mathrm{S}$, Berkels R, et al. Reaction rate constants of superoxide scavenging by plant antioxidants. Free Radic Biol Med 2003; 35: 1599-1607, doi: 10.1016/j.freeradbiomed.2003. 09.005 .

23. Choi DC, Lee JY, Lim EJ, Baik HH, Oh TH, Yune TY. Inhibition of ROS-induced p38MAPK and ERK activation in microglia by acupuncture relieves neuropathic pain after spinal cord injury in rats. Exp Neurol 2012; 236: 268-282, doi: 10.1016/j.expneurol.2012.05.014.

24. Alves-Filho JC, Sonego F, Souto FO, Freitas A, Verri WA Jr, Auxiliadora-Martins $M$, et al. Interleukin-33 attenuates sepsis by enhancing neutrophil influx to the site of infection. Nat Med 2010; 16: 708-712, doi: 10.1038/nm.2156.

25. Guerrero AT, Verri WA Jr, Cunha TM, Silva TA, Schivo IR, Dal-Secco D, et al. Involvement of LTB4 in zymosaninduced joint nociception in mice: participation of neutrophils and PGE2. J Leukoc Biol 2008; 83: 122-130, doi: 10.1189/ jlb.0207123. 
26. Zarpelon AC, Cunha TM, Alves-Filho JC, Pinto LG, Ferreira $\mathrm{SH}$, McInnes IB, et al. IL-33/ST2 signalling contributes to carrageenin-induced innate inflammation and inflammatory pain: role of cytokines, endothelin-1 and prostaglandin E2. Br J Pharmacol 2013; 169: 90-101, doi: 10.1111/bph.12110.

27. Verri WA Jr, Cunha TM, Magro DA, Guerrero AT, Vieira SM, Carregaro $\mathrm{V}$, et al. Targeting endothelin ETA and ETB receptors inhibits antigen-induced neutrophil migration and mechanical hypernociception in mice. Naunyn Schmiedebergs Arch Pharmacol 2009; 379: 271-279, doi: 10.1007/ s00210-008-0360-1.

28. Kim HY, Chung JM, Chung K. Increased production of mitochondrial superoxide in the spinal cord induces pain behaviors in mice: the effect of mitochondrial electron transport complex inhibitors. Neurosci Lett 2008; 447: 8791, doi: 10.1016/j.neulet.2008.09.041.

29. Nishio N, Taniguchi W, Sugimura YK, Takiguchi N, Yamanaka M, Kiyoyuki $\mathrm{Y}$, et al. Reactive oxygen species enhance excitatory synaptic transmission in rat spinal dorsal horn neurons by activating TRPA1 and TRPV1 channels. Neuroscience 2013; 247: 201-212, doi: 10.1016/j.neuro science.2013.05.023.

30. Muscoli C, Mollace V, Wheatley J, Masini E, Ndengele M,
Wang ZQ, et al. Superoxide-mediated nitration of spinal manganese superoxide dismutase: a novel pathway in $\mathrm{N}$ methyl-D-aspartate-mediated hyperalgesia. Pain 2004; 111: 96-103, doi: 10.1016/j.pain.2004.06.004.

31. Ko YK, Youn AM, Hong BH, Kim YH, Shin YS, Kang PS, et al. Antinociceptive effect of phenyl N-tert-butylnitrone, a free radical scavenger, on the rat formalin test. Korean $J$ Anesthesiol 2012; 62: 558-564, doi: 10.4097/kjae.2012. 62.6.558.

32. Robak J, Gryglewski RJ. Flavonoids are scavengers of superoxide anions. Biochem Pharmacol 1988; 37: 837-841, doi: 10.1016/0006-2952(88)90169-4.

33. Morikawa K, Nonaka M, Narahara M, Torii I, Kawaguchi K, Yoshikawa $\mathrm{T}$, et al. Inhibitory effect of quercetin on carrageenan-induced inflammation in rats. Life Sci 2003; 74: 709-721, doi: 10.1016/j.lfs.2003.06.036.

34. Kim HY, Wang J, Lu Y, Chung JM, Chung K. Superoxide signaling in pain is independent of nitric oxide signaling. Neuroreport 2009; 20: 1424-1428, doi: 10.1097/WNR. Ob013e328330f68b.

35. Kress M, Riedl B, Reeh PW. Effects of oxygen radicals on nociceptive afferents in the rat skin in vitro. Pain 1995; 62: 87-94, doi: 10.1016/0304-3959(94)00254-C. 